\section{EVICR.net Activities - Update}

EVICR.net - the European Vision Institute Clinical Research Network - is a network dedicated to perform multinational clinical research in ophthalmology with the highest standards of quality following the European and International Directives for Clinical Research according to harmonized standard operating procedures (SOPs). The network is a useful resource for the development and the coordination of investigator-initiated research (IIR) and for industry-driven clinical trials, contributing to strengthen the capacity of the European Union to explore and optimise diagnostic, prevention and treatment strategies in ophthalmology.

This European platform for multinational translational research in ophthalmology has presently 99 Clinical Site Members from 18 European countries as well as 7 industry partners, aiming to respond to the challenges of an increasing demand of better health-care assistance in ophthalmology.

The EVICR.net Coordinating Centre is located at AIBILI in Coimbra, Portugal, which is responsible for the management of the network and multinational clinical research.

\section{Aims and Objectives}

The main aims and objectives of EVICR.net are:

- to guarantee a high level of quality and excellence in the multinational clinical research performed according to International Conference on Harmonisation - Good Clinical Practice (ICH-GCP) Guidelines,

- to promote multinational IIR within the European Union,

- to serve as a resource for industry in performing clinical research in ophthalmology,

- to coordinate training activities for its members,

- to promote quality, transparency and optimal use of clinical research data, and

- to inform patients and citizens of the challenges and opportunities raised in ophthalmology clinical research.

\section{Organization}

The General Assembly consists of all EVICR.net members and is the supreme organ of the network.

The Steering Committee is responsible for the activities of the EVICR.net and acts as its decision-making body within the framework set by the General Assembly. The Steering Committee consists of up to 7 representatives: the Chairman, the Coordinator of each Expert Committee and the CEO of the Coordinating Centre.

The Expert Committees have a fundamental role in the scientific organization of EVICR.net and cover the following main areas of research: AMD and Retinal Dystrophies, Diabetic Retinopathy and Vascular Diseases, Glaucoma, Anterior Segment, and Reading Centres.

There are also two Transversal Sections that work together with the Expert Committees when applicable: Medical Devices and Rare Diseases.

The Industry Advisory Board advises the Steering Committee in all matters of strategic relevance, particularly pertaining collaborations with industry. The Industry Advisory Board is composed of individuals or representatives of companies who have given support to the activities of EVICR.net and at the moment is composed of Alcon, Allergan, Bayer, Novartis, Pfizer, Santen and Théa.

The Coordinating Centre, AIBILI, is the contact point for the members and industry when performing ophthalmological clinical research in Europe. The Coordinating Centre is responsible for the coordination of IIR. Annually, the Coordinating Centre updates the EVICR.net Research Resources Directory where all members have their resources listed: staff, equipment and facilities as well as their scientific areas of clinical research and the 5 most relevant publications. All members have access to a restricted area on the website that is also kept updated by the Coordinating Centre. The Coordinating Centre is responsible for the certification of EVICR.net Clinical Site Members.

\section{KARGER}

E-Mail karger@karger.com

www.karger.com/ore
(C) 2016 S. Karger AG, Basel

$0030-3747 / 16 / 0563-0163 \$ 39.50 / 0$ 
Table 1. Number of members per country

\begin{tabular}{lr}
\hline Austria & 1 \\
Belgium & 3 \\
Denmark & 2 \\
Finland & 1 \\
France & 12 \\
Germany & 15 \\
Greece & 1 \\
Ireland & 1 \\
Israel & 3 \\
Italy & 10 \\
Poland & 1 \\
Portugal & 13 \\
Slovakia & 1 \\
Slovenia & 1 \\
Spain & 15 \\
Switzerland & 5 \\
The Netherlands & 5 \\
United Kingdom & 9 \\
\hline Total & 99 \\
\hline
\end{tabular}

Table 2. Multinational clinical research studies (2010-2016)

\begin{tabular}{llllll}
\hline Year & IIR & & & \multirow{2}{\text{Industry}}{$\begin{array}{c}\text { Total } \\
\text { registries }\end{array}$} & \\
& $\begin{array}{l}\text { no } \\
\text { funding }\end{array}$ & $\begin{array}{l}\text { EU } \\
\text { funding }\end{array}$ & $\begin{array}{l}\text { industry } \\
\text { grant }\end{array}$ & & \\
\hline 2010 & 2 & - & - & - & 2 \\
2011 & 2 & 1 & - & - & 3 \\
2012 & 2 & 2 & 1 & 2 & 7 \\
2013 & 2 & 3 & 3 & 3 & 11 \\
2014 & 2 & 3 & 4 & 3 & 12 \\
2015 & - & 3 & 4 & 2 & 9 \\
2016 & - & 3 & 4 & 1 & 8 \\
\hline
\end{tabular}

\section{Annual Members Meeting}

The 10th Annual Members Meeting took place in Rome, Italy, on November 26-27, 2015. The meeting was attended by about 100 participants from member centres (table 1; fig. 1), contract research organizations (CROs) and Industry Advisory Board members. The 11th EVICR.net Annual Meeting will take place in Antwerp, Belgium, on November 9-10, 2016.

\section{Investigator-Initiated Research and Registries}

The EVICR.net Coordinating Centre is responsible for the coordination and management of IIR in ophthalmology across Europe through the network. EVICR.net members have the opportunity to submit abstracts for IIR to the Coordinating Centre in

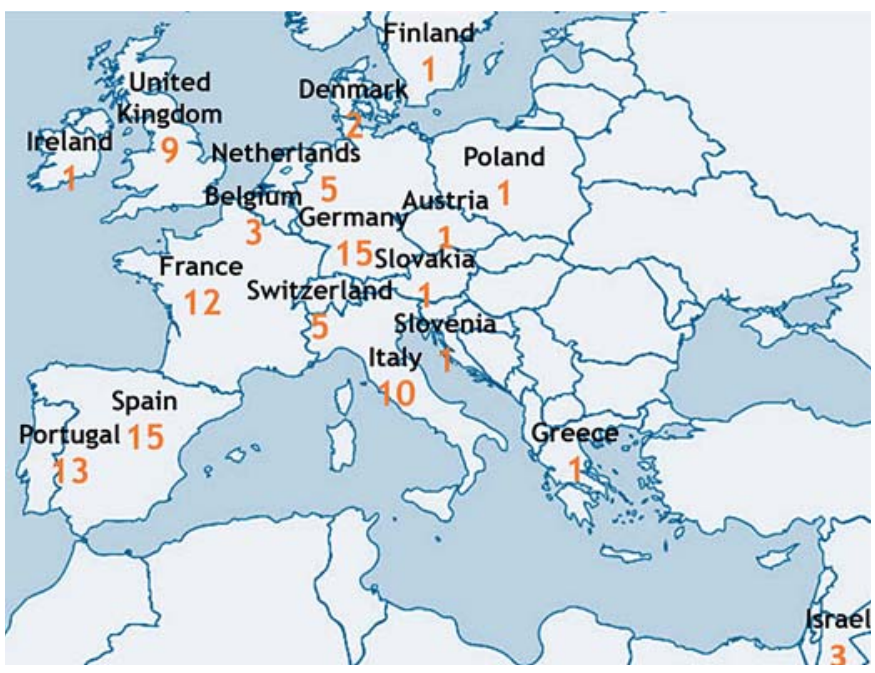

Fig. 1. Number of members per country (a total of 99 sites).

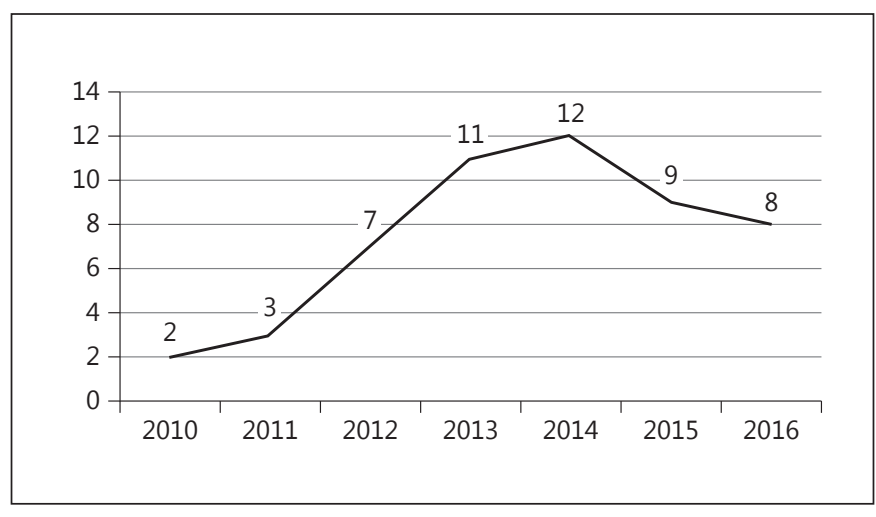

Fig. 2. Number of multinational clinical research studies.

order to be evaluated by a specific Expert Committee. If approved, they will have access to support in developing and implementing the IIR. Also, EVICR.net members have the opportunity to participate in IIR developed by the network or in industry-sponsored clinical trials.

EVICR.net IIR has been growing in the last years, giving the opportunity to investigators to perform multinational clinical research of high quality (ICH-GCP compliant), assuming that the rights, safety and wellbeing of the trial subjects are protected and that the clinical data are credible. EVICR.net has contributed to the improvement of diagnostic, prevention and treatment strategies in ophthalmology. EVICR.net has presently 8 ongoing multinational clinical research studies, of which 3 are European Union funded, 4 obtained industry grants and 1 is an industry registry (tables 2, 3; fig. 2). 
Table 3. Multinational clinical research studies per ophthalmology subspecialty (May 2016)

\begin{tabular}{|c|c|c|c|c|}
\hline \multirow[t]{2}{*}{ Ongoing clinical research } & \multicolumn{4}{|l|}{ Area of subspecialty } \\
\hline & $\begin{array}{l}\text { AMD and Retinal } \\
\text { Dystrophies }\end{array}$ & $\begin{array}{l}\text { Diabetic Retinopathy and } \\
\text { Vascular Diseases }\end{array}$ & Glaucoma & $\begin{array}{l}\text { Anterior } \\
\text { Segment }\end{array}$ \\
\hline Clinical trials (IIR) & $\begin{array}{l}\text { Eur-USH }^{\mathrm{a}} \\
\text { ATLANTIC }^{\mathrm{b}}\end{array}$ & $\begin{array}{l}\text { EUROCONDOR }^{\mathrm{a}} \\
\text { PROTEUS }^{\mathrm{b}} \\
\text { ARTES }^{\mathrm{b}}\end{array}$ & $\begin{array}{l}\text { STRONG }^{\mathrm{a}} \\
\text { SPORT }^{\mathrm{b}}\end{array}$ & \\
\hline Registry (industry) & & IRISS & & \\
\hline Total & 2 & 4 & 2 & 0 \\
\hline
\end{tabular}

${ }^{\mathrm{a}}$ EU-funded. ${ }^{\mathrm{b}}$ Industry grant.

\section{AMD and Retinal Dystrophies}

Clinical Trials

1 Eur-USH - European Young Investigators Network for Usher Syndrome. EU-funded project. ClinicalTrials.gov No. NCT01954953.

2 ATLANTIC - A randomized, double-masked, sham-controlled phase 4 study of the efficacy, safety and tolerability of intravitreal aflibercept monotherapy compared to aflibercept with adjunctive photodynamic therapy in patients with polypoidal choroidal vasculopathy. IIR grant from Bayer. EudraCT No. 2015-001368-20; ClinicalTrials.gov No. NCT02495181.

\section{Diabetic Retinopathy and Vascular Diseases} Clinical Trials

1 EUROCONDOR - Neurodegeneration as an early event in the pathogenesis of diabetic retinopathy: a multicentric, prospective, phase II/III, double-blind randomized controlled trial to assess the efficacy of neuroprotective drugs administered topically to prevent or arrest diabetic retinopathy. EU-funded project. EudraCT No. 2012-001200-38; ClinicalTrials.gov No. NCT01726075.

2 PROTEUS - Prospective, randomized, multicenter, open-label, phase II/III study to assess the efficacy and safety of ranibizumab $0.5 \mathrm{mg}$ intravitreal injections plus panretinal photocoagulation (PRP) versus PRP in monotherapy in the treatment of patients with high-risk proliferative diabetic retinopathy. IIR grant from Novartis. EudraCT No. 2013-003640-23; ClinicalTrials.gov No. NCT01941329.

3 ARTES - A collaborative retrospective trial on the efficacy and safety of intravitreal dexamethasone implant (Ozurdex) in patients with diabetic macular edema (DME). IIR grant from Allergan. ClinicalTrials.gov No. NCT02121197.

Registry

1 IRISS - An open-label registry study of the safety of Iluvien ${ }^{\circledR}$ (fluocinolone acetonide $190 \mu \mathrm{g}$ intravitreal implant in applicator). Sponsor: Alimera. ClinicalTrials.gov No. NCT01998412.

\section{Glaucoma}

Clinical Trials

1 STRONG - European Consortium for the Study of a Topical Treatment of Neovascular Glaucoma. EU-funded project.
2 SPORT - A randomized, 3-month, crossover, single-masked, investigator-led, multicenter trial on open-angle glaucoma or ocular hypertension patients. IIR grant from Allergan. EudraCT No. 2013-003490-10; ClinicalTrials.gov No. NCT01975714.

\section{Publications}

AMD and Retinal Dystrophies

- ECR-ICT-09 - LHON - A registry on Leber's Hereditary Optic Neuropathy. Sponsor: Santhera. ClinicalTrials.gov No. NCT01892943.

- EVER 2014 (poster)

Diabetic Retinopathy and Vascular Diseases

- ECR-RET-2010-02 - Identifying progression of retinal disease in eyes with non-proliferative diabetic retinopathy in diabetes type 2 using non-invasive procedures. ClinicalTrials.gov No. NCT01145599.

- ARVO 2014 Congress (poster)

- ARVO 2015 Congress (poster)

- Invest Ophthalmol Vis Sci 2015;56:5698-5705

- Ophthalmic Res 2015;54:112-117

- Ophthalmic Res 2015;54:118-123

- Ophthalmic Res 2015;55:19-25

- ECR-RET-2011-03 - EUROCONDOR - Neurodegeneration as an early event in the pathogenesis of diabetic retinopathy: a multicentric, prospective, phase II/III, double-blind randomized controlled trial to assess the efficacy of neuroprotective drugs administered topically to prevent or arrest diabetic retinopathy. EU-funded project. EudraCT No. 2012-001200-38; ClinicalTrials.gov No. NCT01726075.

- Br J Ophthalmol 2012;96:1285-1290

- ARVO 2014 Congress (poster)

- Trends Endocrinol Metab 2014;25:23-33

- ARVO 2015 Congress (poster)

- Invest Ophthalmol Vis Sci 2015;56:1802

- ARVO 2016 Congress (poster)

- EASDec 2016 (5 presentations) 
Glaucoma

- ECR-GLC-2013-06 - SPORT. EudraCT No. 2013-003490-10; ClinicalTrials.gov No. NCT01975714.

- COPHy 2015 (poster)

- Graefes Arch Clin Exp Ophthalmol 2016;254(6):1151-1158

\section{Anterior Segment}

- ECR-CCRS-2010-01 - Project Gullstrand - European Project for the Determination of Average Biometric Values of Human Eyes. ClinicalTrials.gov No. NCT01173614.

- Cah Ophtalmol 2013;170:40-42

- ARVO 2014 (2 presentations)

- Optom Vis Sci 2014;91:1-10

- ESCRS 2013 (poster)

- Invest Ophthalmol Vis Sci 2015;56:7029-7035

- Poster accepted to be presented in the VPO 2016 Congress

- BMC Ophthalmol 2016; paper accepted for publication

\section{Standard Operating Procedures}

EVICR.net has developed a quality system for its members compliant with ICH-GCP Guidelines. It provides 9 Organizational SOPs for free to its members. All EVICR.net Clinical Sites Members agree to adopt or adapt these SOPs in their centres, which will be checked before they are certified as Sites of Excellence. An independent evaluation visit may occur before this certification.

The implementation of these 9 Organizational SOPs will permit the Clinical Sites to have a common standard way of working and in compliance with ICH-GCP Guidelines when performing clinical research.

EVICR.net has also developed 31 Technical SOPs for performing specific ophthalmic examinations or evaluations that can be used within the Network for Clinical Trials. These SOPs are also made available to our members.

In parallel, EVICR.net has developed 22 Organizational SOPs for the Reading Centres so they can work as a network of Reading Centres and be able to have the capacity to respond to the industry needs for grading ophthalmological images in a standardised way with the most novel equipment.

\section{Clinical Sites Certification}

At the moment, we have 57 Clinical Sites certified, of which 46 are re-certified (more than 2-year certificate).

\section{Educational Programme}

An Educational Programme is being implemented within the EVICR.net activities. On April 10, 2016, an OCT Course took place in Milan, Italy, in association with the 2nd San Raffaele OCT Forum. Another OCT Course is now planned to take place in association with the 11th Annual Members Meeting in Antwerp, Belgium, on November 9-10, 2016.

A programme with CME credits is now being organized on Clinical Research Methodologies as they are applied to ophthalmology and investigator-initiated clinical research trials.

\section{Collaboration with ECRIN - European Clinical Research Infrastructure Network}

EVICR.net, as a disease-oriented network in ophthalmology for clinical research, is an affiliate partner of ECRIN-ERIC, the European Clinical Research Infrastructure Network.

Since ECRIN-ERIC is a network for investigator-initiated multicentre clinical research in Europe in any scientific area, EVICR.net serves as a resource to ECRIN-ERIC in the area of vision and ophthalmology clinical research, particularly providing scientific and medical expertise, access to patients and clinical research capacity in ophthalmology through its members in an organized manner and compliant with ICH-GCP Guidelines and the European Regulation for Clinical Research.

\section{Alliances and Partnerships}

EVICR.net has established preferred alliances with two CROs, AppleTree (Switzerland) and Eurotrials (Portugal), for the EVICR.net Clinical Site certification process to perform an independent evaluation visit of the Clinical Sites.

Collaborations are being established with other CROs in order to move forward multinational clinical research in ophthalmology.

\section{EVICR.net - European Network of Clinical Research in Ophthalmology}

Chairman

Jose Sahel, MD, PhD

Steering Committee

Jose Sahel, MD, PhD - AMD and Retinal Dystrophies Expert Committee Coordinator

José Cunha-Vaz, MD, PhD - Diabetic Retinopathy and Vascular Diseases Expert Committee Coordinator

Francesca Cordeiro, MD, PhD - Glaucoma Expert Committee Coordinator

Marie-José Tassignon, MD, PhD - Anterior Segment Expert Committee Coordinator

Tunde Peto, MD, PhD, FHCO, FHCD - Reading Centres Expert Committee Coordinator

Jorge Alió, MD, PhD - Medical Devices Transversal Section Coordinator

Birgit Lorenz, MD, PhD - Rare Diseases Transversal Section Coordinator

Cecília Martinho, BSc - CEO, Coordinating Centre (AIBILI)

Contacts

EVICR.net

AIBILI, Azinhaga de Santa Comba, Celas

PT-3000-548 Coimbra (Portugal)

Tel. +351 239480 101/15, Fax +351 239480117

E-Mail evicrnet@aibili.pt, Website www.evicr.net 


\section{List of EVICR.net Members (per Country)}

\begin{tabular}{ll}
$\begin{array}{l}\text { Austria (1) } \\
\text { CS No. 19: }\end{array}$ & $\begin{array}{l}\text { Medical University of Vienna, Department of } \\
\text { Ophthalmology, Vienna }\end{array}$ \\
\hline $\begin{array}{l}\text { Belgium (3) } \\
\text { CS No. 8: }\end{array}$ & $\begin{array}{l}\text { Ghent University Hospital, Department of } \\
\text { Ophthalmology, Ghent } \\
\text { Antwerp University Hospital, Department of } \\
\text { CS No. 12: }\end{array}$ \\
Ophthalmology, Antwerp \\
University Hospitals Leuven, Department of \\
Ophthalmology, Leuven
\end{tabular}

France (12)

CS No. 3 :

Centre Hospitalier Creteil, University Eye Clinic, Paris

CS No. 6: Centre National d'Ophthalmologie des Quinze-

CS No. 13: Vingts, Centre d'Investigation Clinique, Paris CHU Gabriel Montpied, Unité de Recherche Clinique, Service d'Ophtalmologie, ClermontFerrand

CS No. 14: $\quad$ Hôpital Lariboisière, Department of Ophthalmology, Paris

CS No. 42: $\quad$ University Hospital, CHU Dijon, Department of Ophthalmology, Dijon

CLAIROP - Centre Loco-Regional de l'AP-HP Necker pour l'Innovation et la Recherche en Ophtalmologie Pediatrique, Paris

CS No. 61:

CS No. 86: CHU Pellegrin, Service Ophtalmologie, Bordeaux Centre Hospitalier Universitaire Amiens-Picardie, Service d'Ophtalmologie, Amiens

CS No. 92: Clinical Trial Unit, Department of Ophthalmology, CHU Nord, Aix Marseille University, Marseille Department of Ophthalmology, Centre Hospitalier Henri Duffaut, Avignon

CS No. 93: Centre Ophtalmologique de l'Odeon, Paris

CS No. 97:

CS No. 99:

Department of Ophthalmology, Croix Rousse University Hospital, Lyon

Germany (15)

CS No. 2:

University Medical Center, Johannes Gutenberg University, Department of Ophthalmology, Mainz

CS No. 5: Faculty of Medicine Mannheim of the RuprechtKarls-University Heidelberg, Department Ophthalmology, Mannheim

CS No. 9: University Hospital Tübingen (UKT), STZ Biomed \& STZ Eyetrial, Center for Ophthalmology, Tübingen

CS No. 11: University Eye Hospital Munich, Munich

CS No. 15: University of Bonn, Department of Ophthalmology, Bonn

CS No. 21: University Medical Center Hamburg-Eppendorf, Department of Ophthalmology, Hamburg

CS No. 24: University of Freiburg, Department of Ophthalmology, Freiburg

CS No. 27: University Eye Hospital, Leipzig

CS No. 43
CS No. 44:

CS No. 54:

CS No. 56:

CS No. 65:

CS No. 77:

CS No. 111:

Greece (1)

CS No. 71 :

Ireland (1)

Israel (3)

CS No. 60:

CS No. 88:

CS No. 100:

Italy (10)

CS No. 16:

CS No. 20:

CS No. 34:

CS No. 36:

CS No. 37:

CS No. 39:

CS No. 50:

CS No. 63:

CS No. 64:

CS No. 67:

University Eye Clinic, Center for Vision Science, Bochum

University of Düsseldorf, Department of Ophthalmology, Düsseldorf

University of Heidelberg, International Vision Correction Research Centre (IVCRC), Heidelberg Justus-Liebig-University Giessen, Department of Ophthalmology, Giessen

Universität zu Köln, Zentrum für Augenheilkunde, Cologne

University of Münster Medical Center, Department of Ophthalmology, Münster

Laboratory of Research and Clinical Applications in Ophthalmology, Aristotle University of Thessaloniki, 1st Department of Ophthalmology, AHEPA University Hospital, Thessaloniki

Mater Vision Institute (MVI), Dublin

Tel Aviv Sourasky Medical Center, Department of Ophthalmology, Tel Aviv

Kaplan Medical Center, Ophthalmology Department, Rehovot

Meir Medical Center, Kfar-Saba

University of Milan, Centre for Clinical Trials at San Paolo Hospital, Milan

G.B. Bietti Foundation - IRCCS, Rome

Luigi Sacco Hospital, University of Milan,

Department of Ophthalmology, Milan

Catholic University, Institute of Ophthalmology,

Rome

Dipartimento di Scienze Biomediche,

Biotecnologiche e Traslazionali S.Bi.Bi.T., Parma

University of Padova, Department of Ophthalmology, Center for Clinical Trials, Padova

University of Udine, Department of Ophthalmology, Udine

University G. d'Annunzio of Chieti-Pescara,

Excellence Eye Research Centre, Chieti

Ophthalmic Research Unit, Department of Basic

Medical Sciences, Neuroscience and Sense Organs,

Bari

University Vita Salute - Scientific Institute of San

Raffael, Department of Ophthalmology, Milan

Poland (1)

CS No. 33:

Poznan University of Medical Sciences, Department of Ophthalmology, Poznan

Portugal (13)

CS No. 1 :

AIBILI - Association for Innovation and Biomedical

CS No. 28:

Research on Light and Image, Coimbra

CS No. 32:

Instituto de Oftalmologia Dr. Gama Pinto, Lisbon

Oporto Medical School - Hospital S. João,

Department of Ophthalmology, Oporto

CS No. 62:

Centro Hospitalar de Lisboa Central, Centro de Investigação, Serviço de Oftalmologia, Lisbon

CS No. 70: University Hospital of Coimbra, Ophthalmology Department, Coimbra 
CS No. 80:

CS No. 82:

CS No. 90:

CS No. 101:

CS No. 102:

CS No. 103:

CS No. 104:

CS No. 107:

\section{Slovakia (1)}

CS No. 87:

Department of Ophthalmology, University Hospital, Comenius University, Bratislava

\begin{tabular}{ll}
\hline Slovenia (1) & \\
CS No. 23: & University Medical Centre of Ljubljana, University \\
& Eye Hospital, Ljubljana \\
\hline Spain (15) & \\
CS No. 7: & Vissum Corporación Oftalmológica Alicante, \\
& Alicante \\
CS No. 26: & Centro de Oftalmología Barraquer, Barcelona \\
CS No. 38: & Institut Català de Retina (ICR), Clinical Trial Unit, \\
& Barcelona \\
CS No. 41: & Centro Médico Teknon, Institut de la Màcula i de la \\
& Retina, Barcelona \\
CS No. 51: & Fundación para la Investigacion Biomedica y \\
& Sanitaria (FISABIO) - Oftalmología Médica, \\
& Valencia \\
CS No. 52: & Universitary Hospital Josep Trueta of Girona, \\
& Department of Ophthalmology, Girona \\
CS No. 74: & Hospital Vall d'Hebrón, Department of \\
& Ophthalmology, Barcelona \\
CS No. 75: & Vallés Oftalmologia Research, Barcelona \\
CS No. 78: & Instituto Oftalmológico Fernández-Vega, Oviedo \\
CS No. 89: & Dos de Maig Hospital, Ophthalmology Department, \\
& Barcelona \\
CS No. 95: & Instituto de Microcirugia Ocular, Barcelona \\
CS No. 96: & Ophthalmology Department, Hospital de LaPaz, \\
& Madrid \\
CS No. 98: & Servicio Oftalmología, Hospital Universitario y \\
& Politécnico de la Fe, Valencia \\
CS No. 105: & Unidad Clínica de Retina - Servicio de Oftalmología, \\
& Complejo Hospitalario Universiterio de Albacete, \\
CS No. 109: & Albacete \\
& Fundación Jiménez Díaz University Hospital, \\
& Department of Ophthalmology, Madrid \\
\hline &
\end{tabular}

Switzerland (5)

CS No. 22: Inselspital, University of Bern, Department of Ophthalmology, Bern

CS No. 49: $\quad$ Jules Gonin Eye Hospital, Fondation Asile des Aveugles, Lausanne

CS No. 85: $\quad$ Clinical Research Centre, Mémorial A. de Rothschild, Geneva

CS No. 108: $\quad$ MIOS SA, Lausanne

CS No. 110: University Hospital Basel, University Eye Clinic, Basel

The Netherlands (5)

CS No. 17:

Department of Ophthalmology, Radboud University Medical Centre, Nijmegen

CS No. 25: $\quad$ Academic Medical Center, Department of Ophthalmology, Amsterdam

CS No. 40: $\quad$ Rotterdam Eye Hospital, Rotterdam

CS No. 76: University Eye Clinic, Maastricht

CS No. 106: Department of Ophthalmology, Leiden University Medical Center, Leiden

United Kingdom (9)

CS No. 10:

NIHR Moorfields Clinical Research Facility, Moorfields Eye Hospital, NHS Foundation Trust, London

CS No. 35: The Queen's University and Royal Group of Hospital Trust, Ophthalmology and Vision Science, Belfast

CS No. 53: Gloucestershire Hospital NHS Foundation Trust, Clinical Trials Unit, Department of Ophthalmology, Cheltenham

CS No. 58: Royal Liverpool University Hospital, Clinical Eye Research Centre, St. Paul's Eye Unit, Liverpool

CS No. 66: Frimley Park Hospital Foundation Trust, Ophthalmology Clinical Trials Unit, Frimley

CS No. 68: Heart of England NHS Trust, Ophthalmic Research Unit, Birmingham

CS No. 69: King's Health Partners, Laser and Retinal Research Unit, London

CS No. 81: $\quad$ Royal Surrey County Hospital, NHS Foundation Trust, Ophthalmic Research Unit, Guildford

CS No. 84: $\quad$ ICORG - Imperial College Ophthalmologic Research Group, London

Prepared by C. Martinho, D. Fernandes and M.V. Nascimento. 